\title{
Assessment of bone ingrowth potential of biomimetic hydroxyapatite and brushite coated porous E-beam structures
}

\author{
J. Elizabeth Biemond • Tatiane S. Eufrásio • \\ Gerjon Hannink • Nico Verdonschot • \\ Pieter Buma
}

Received: 16 November 2010/ Accepted: 6 February 2011/Published online: 16 February 2011

(c) The Author(s) 2011. This article is published with open access at Springerlink.com

\begin{abstract}
The bone ingrowth potential of biomimetic hydroxyapatite and brushite coatings applied on porous E-beam structure was examined in goats and compared to a similar uncoated porous structure and a conventional titanium plasma spray coating. Specimens were implanted in the iliac crest of goats for a period of 3 (4 goats) or 15 weeks (8 goats). Mechanical implant fixation generated by bone ingrowth was analyzed by a push out test. Histomorphometry was performed to assess the bone ingrowth depth and bone implant contact. The uncoated and hydroxyapatite-coated cubic structure had significantly higher mechanical strength at the interface compared to the Ti plasma spray coating at 15 weeks of implantation. Bone ingrowth depth was significantly larger for the hydroxyapatite- and brushite-coated structures compared to the uncoated structure. In conclusion, the porous E-beam surface structure showed higher bone ingrowth potential compared to a conventional implant surface after 15 weeks of implantation. Addition of a calcium phosphate coating to the E-beam structure enhanced bone ingrowth significantly. Furthermore, the calcium phosphate coating appears to work as an accelerator for bone ingrowth.
\end{abstract}

J. E. Biemond $(\bowtie) \cdot$ G. Hannink · N. Verdonschot · P. Buma Orthopaedic Research Laboratory, Radboud University Nijmegen Medical Center, P.O. Box 9101, 6500, HB, Nijmegen, The Netherlands

e-mail: L.Biemond@ orthop.umcn.nl

T. S. Eufrásio

Department Materials Engineering and Industrial Technologies, University of Trento, Via Mesiano 77, 38050 Trento, Italy

N. Verdonschot

Laboratory for Biomechanical Engineering, University of

Twente, P.O.Box 217, 7500, AE, Enschede, The Netherlands

\section{Introduction}

Total hip arthroplasty is one of the most successful medical procedures. However, 5 to $10 \%$ of the cementless implants still fail within 10 years of implantation $[1,2]$. The frequency of failure is likely to increase due to the implantation in younger and more active patients [3]. The long term success of cementless orthopaedic implants depends on biological fixation by new bone formation [4-6]. Surface topography (e.g. pore size, porosity) and coating influence the process of bone ingrowth and by that the fixation in the critical postoperative period. It is evident that the size of the pores affects bone ingrowth, although there is still debate about the optimum pore size [7-9]. A minimum pore diameter of $100 \mu \mathrm{m}$ is needed to allow vascularisation and bone ingrowth [10]. The maximum pore size has yet to be determined. It has been shown that enhanced fixation strength can be obtained by increasing the porosity of an implant up to 75-80\% [11]. However, full bone ingrowth takes more time in implants with increased porosity, whereas fast bone formation permits more rapid loading of the implant [12].

Electron beam melting is a rapid prototyping technology that can be used to produce implants with computer designed surface characteristics. The implant is build up out of metal powder to reproduce a geometry defined by a three-dimensional CAD model. The technique enables for production of the solid core and the porous surface in one manufacturing step, with the capability to engineer a large variety of complex three-dimensional structures as implant surface [13-15]. Ponader et al. [16] showed that osteoblastic cells attach, proliferate and differentiate well on new developed E-beam produced surface structures. Previous work of our group showed that the bone ingrowth potential of these porous E-beam surface topographies was 
comparable to a clinical used, conventionally made surface. However, as can be expected for a highly porous surface, complete bone ingrowth was not reached in a post operative period of 6 weeks [17].

Calciumphosphate $(\mathrm{CaP})$ coatings have been successfully applied on orthopedic and dental implants [18-21]. Stimulation of new bone formation around $\mathrm{CaP}$ coated implants is based on dissolution of the coating soon after implantation followed by formation of a bone-inductive carbonated calcium phosphate layer [20]. The biological advantages of these coatings include the enhancement of bone formation and accelerated bonding between the implant surface and the surrounding bone [20, 22, 23]. Calcium phosphate coatings can be applied on porous implant surfaces in order to enhance the bone ingrowth potential [21, 22]. Furthermore, the acceleration of bone ingrowth that can be achieved by these coatings could be beneficial regarding to shortening the post-operative partial weight-bearing and rehabilitation periods [18].

Although the calciumphosphate coatings are applied successfully on implant surfaces, current direct coating techniques failed to mineralize on the deep surfaces of complex three-dimensional structures [24]. Biomimetic coating deposition is a relatively new coating technique with the possibility to produce a homogeneous coating on these complex three-dimensional structures. The coating is deposited under physiological temperatures, which makes it possible to incorporate functional biological agents, such as growth factors, in the coating. In addition, the $\mathrm{CaP}$ ratio and coating thickness can be varied, and the structure of the formed crystals is more akin to bone mineral than those produced in conventional ways $[18,24]$.

For this study a porous E-beam structure was combined with two biomimetic $\mathrm{CaP}$ coatings. It was hypothesized that these $\mathrm{CaP}$ coated E-beam structures would provide for accelerated and enhanced bone ingrowth. Therefore the goal of this study was to characterize the materials in detail and to assess the mechanical strength of the bone-implant interface and the bone ingrowth potential of a porous E-beam implant surface structure coated with a hydroxyapatite and brushite calciumphosphate coating and to compare this to an uncoated E-beam structure and a conventionally made implant surface.

\section{Materials and methods}

\subsection{Specimens}

The implants were made out of Ti6Al4V powder and produced with E-beam technology (Eurocoating, Trento, Italy). The powder particles used ranged from 45 to
$100 \mu \mathrm{m}$ and were melted by the electron beam into the desired shapes based on CAD data. In short, a homogeneous powder layer was applied on the process platform in a vacuum chamber at high temperature $\left( \pm 700^{\circ} \mathrm{C}\right)$ and scanned by the electron beam. The powder particles were melted at the programmed locations. The process platform was lowered by one layer thickness $(0.1 \mathrm{~mm})$ after the melting of each layer and the process was repeated [13, 25]. Upon completion, all specimens were sandblasted and cleaned according to protocols for medical implants. The overall accuracy of the E-beam technology in terms of computer model reconstruction is $\pm 0.15 \mathrm{~mm}$.

A three-dimensional structure with quadrangular pores (cubic) was used as surface topography for all E-beam specimens. The cubic structure has a pore size of $1.2 \mathrm{~mm}$ and a porosity of $77 \%$. The structure was applied on two opposite sides of the specimens, the other two sides were closed. The adhesive strength (test described in ASTM F1147) of the E-beam specimens was $>50 \mathrm{MPa}$ and the taber abrasion test (as described in ASTM F1978) showed a weight loss after 100 cycles of $27.78 \pm 4.51 \mathrm{mg}$. One group of cubic specimens was left uncoated (cubic), two were coated afterwards with $\mathrm{CaP}$ coatings. As a control, a commercially available titanium plasma spray coating (TiPS) was tested [26] (Fig. 1).

\subsection{Coatings}

A biomimetic coating was applied on two groups of cubic E-beam specimens. In the biomimetic coating process, a bioactive coating was produced using an electrodeposition system. A calciumphosphate layer was formed on the metallic specimen after immersion in an artificially prepared supersaturated calcium/phosphate electrochemical solution (Eurocoating, Trento, Italy) [19]. The brushite coating obtained with this method, has a high solubility. With a two-step procedure, this high soluble coating can be modified to a hydroxyapatite coating [27].

One group of cubic E-beam specimens was coated with a biomimetic brushite coating (cubicBR). The other group was coated with biomimetic hydroxyapatite (cubicHA).

\subsection{Material characterization}

\subsubsection{Scanning electron microscopy (SEM)}

The surface morphology and coating thickness were examined by scanning electron microscopy (SEM, SEM6310, Jeol, Tokyo, Japan). The SEM was coupled with an energy dispersive X-ray spectroscopy (EDS, JSM5500 , Jeol, Tokyo, Japan) which was used to determine the elemental composition of the biomimetic coatings. 
Fig. 1 Surfaces. Cubic structure (top) and TiPS (bottom). Bar $=2 \mathrm{~mm}$

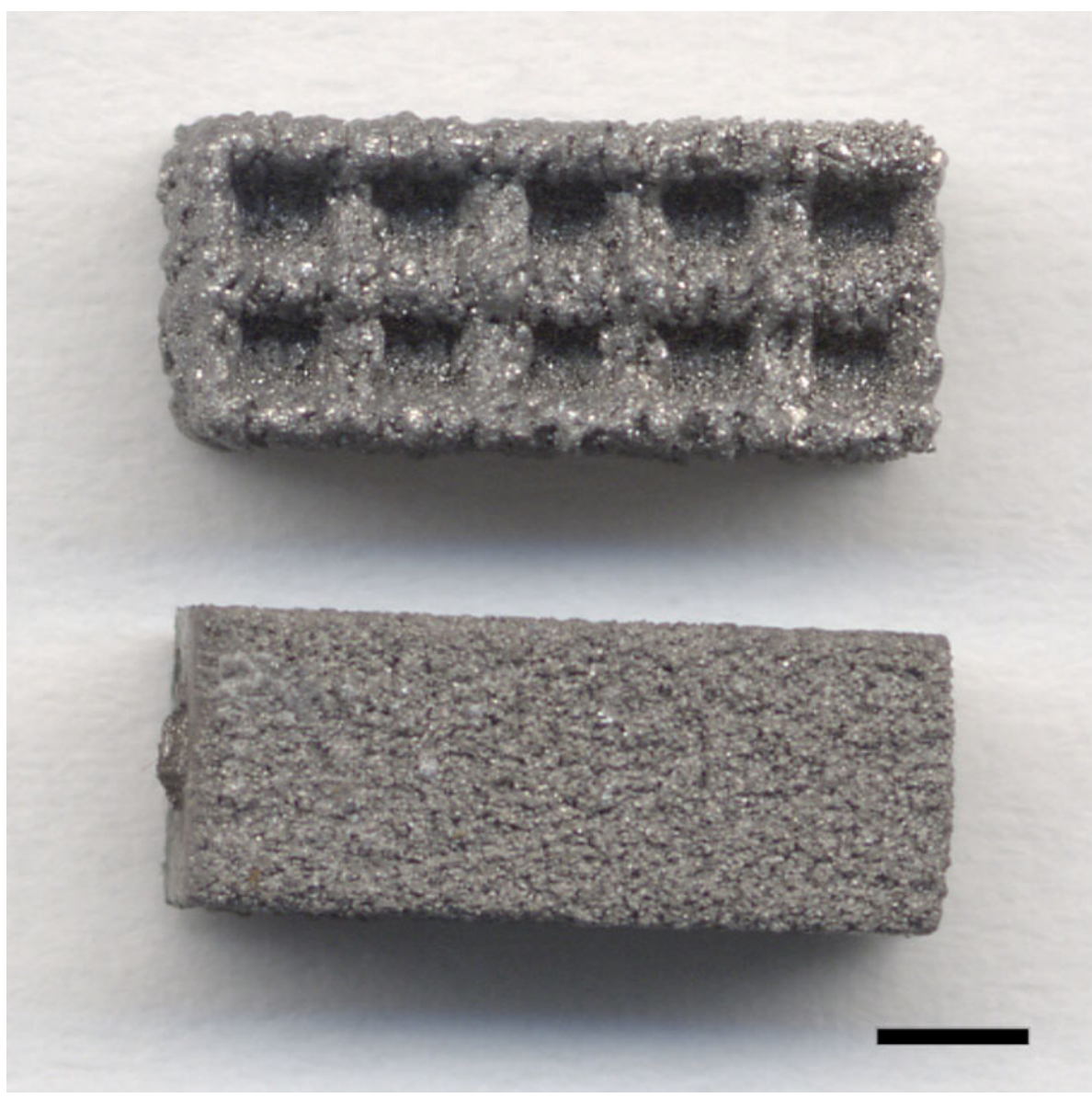

\subsubsection{Roughness}

Surface roughness values of the specimens were determined using a Universal Surface Tester (UST) (Innowep, Wurzburg, Germany).

\subsubsection{In vitro coating dissolution}

The dissolution behavior of the hydroxyapatite and brushite coating was evaluated in vitro. For each group ten samples (cylindrical, $25 \mathrm{~mm}$ height, $\varnothing 10 \mathrm{~mm}$ ) were tested in $\mathrm{pH} 5.5(n=5)$ and in $\mathrm{pH} 7.3(n=5)$. The specimens were positioned in polyethylene bottles filled with $250 \mathrm{ml}$ buffer solution [28] with a $\mathrm{pH}$ of 5.5 and 7.3, using continuous stirring $(200 \pm 10 \mathrm{rpm})$ for 21 days. The bottles were kept at $37.0 \pm 0.1^{\circ} \mathrm{C}$ under nitrogen atmosphere. The $\mathrm{pH}, \mathrm{Ca}$ and $\mathrm{P}$ content were determined daily by drawing $0.5 \mathrm{ml}$ aliquot of each solution. $0.5 \mathrm{ml}$ buffer solution was then added to the bottles to compensate the sampling. The supernatant aliquots were then diluted to be analyzed by inductively coupled plasma atomic emission spectrometry (ICP-AES 76004527, Spectro analytical instruments, Kleve, Germany).

\subsection{Animal experiment}

Surgery was performed on 12 female, skeletal mature goats (Capra Hircus Sana), weighing 43-62 kg (mean $55 \mathrm{~kg}$ ). The specimens $(4 \times 4 \times 10 \mathrm{~mm})$ were implanted in the trabecular bone of the iliac crest [29]. Each goat received eight specimens in total (one set of four specimens for the push out test and one set for histology). The location of the implants was alternated systematically between goats with a random start.

The goats were anaesthetized with propofol $(4 \mathrm{mg} / \mathrm{kg}$ B.Brown, Melsungen, Germany), intubated and anesthesia was maintained using isoflurane. The goats were placed in a prone position and the implantation procedure was performed under strict sterile conditions. A transverse skin incision was made over the iliac crest. The incision was continued subcutaneously to the periosteum. The periosteum was opened, after which the iliac crest was fully exposed. Four implant areas were created in the iliac crest using a sharp drill $(\varnothing 4.0 \mathrm{~mm})$. Saline was used during the drilling to prevent heat induced necrosis. A quadrangular osteotome $(4 \times 4 \mathrm{~mm})$ was used to shape the drilled hole to the size of the specimen. The implantation area was 
inspected to guarantee the specimen was completely surrounded by trabecular bone. The specimens were inserted press-fit into the holes and the periosteum and skin were closed separately with resorbable sutures. This procedure was repeated on the contralateral side.

The goats received postoperative ampicillin $(7.5 \mathrm{mg} / \mathrm{kg}$ Intervet, Boxmeer, The Netherlands) during 4 days and were housed at a farm. The goats were killed by an overdose of sodium pentobarbital (Euthesate, Ceva Santa Animale, Libourne, France). Four goats were sacrificed 3 weeks after surgery, eight goats 15 weeks after surgery. After sacrificing the animals, the iliac crests were retrieved. The goats that were sacrificed 15 weeks after surgery received fluorochromes at 5 (Calcein green $25 \mathrm{mg} / \mathrm{kg}$ ), 10 (Xylenol Orange, $30 \mathrm{mg} / \mathrm{kg}$ ) and 15 weeks (Tetracyclin $25 \mathrm{mg} / \mathrm{kg}$ ). After sacrificing contact X-rays (Faxitron 43805N, Hewlett Packard, Palo Alto, California, USA) were taken of the iliac crests to evaluate the position of the implants. The two medial implants of each iliac crest were used for mechanical testing and the two on the lateral side were used for histological analysis. All procedures have been approved by the animal ethics committee of the Radboud University Nijmegen.

\subsection{Mechanical testing}

The specimens and the surrounding bone were stored in the freezer until the test was performed. Based on the X-ray images the surrounding bone was sawed into a cube with the implant surrounded by bone, the top and bottom of the specimen free of tissues and the implant exactly perpendicular to the surfaces of top and bottom. Subsequently this cube was placed in a jig, which supported only the surrounding bone and not the implanted specimen. The clearance between specimen and support by the jig was $0.7 \mathrm{~mm}$ [30]. The load (MTS, load cell $1 \mathrm{kN}$ ) was placed on top of the specimen and pushed the specimen out the surrounding bone with a fixed speed $(1 \mathrm{~mm} / \mathrm{min})$ and continuous load versus displacement data were recorded. The maximum force was identified in order to define the mechanical strength of the bone-implant interface.

\subsection{Histological analysis}

The specimens for histology were fixated in phosphatebuffered $4 \%$ formaldehyde solution for 4 days and embedded in polymethylacrylate (PMMA). Ten sections of $30 \mu \mathrm{m}$ thickness, perpendicular to the length of the specimen, were prepared using a sawing microtome (SP 1600, Leitz, Wetzlar, Germany).

Quantitative analysis of bone ingrowth was performed using fluorescence microscopy on unstained slices and light microscopy on Hematoxylin/Eosin (HE) stained slices.
Each slice was analyzed blinded in random order using specialized software (AnalySIS 3.2 Soft Imaging System, Münster, Germany). For each specimen all ten sections were analyzed, subsequently the data were pooled.

Bone ingrowth depth was measured at 5,10 and 15 weeks using fluorescence microscopy (group sacrificed at 15 weeks). A line was drawn from the outline of the specimen to the deepest fluorochrome label (perpendicular to the outline of the specimen). The ingrowth depth was defined as the average of this measurement on each side of the specimen. Due to the solid structure of the plasma spray coating, it was impossible to measure bone ingrowth depth for this control. The direct bone-implant contact (BIC) was determined by direct bone surface contact divided by the total surface perimeter of the implant.

\subsection{SEM analysis of coating dissolution}

The implanted hydroxyapatite and brushite coated specimens and their surrounding bone (after implantation), were analyzed by SEM for coating dissolution after sawing sections and polishing the surface of the specimens.

\subsection{Statistical analysis}

Both mechanical (push-out test) and histological (bone ingrowth depth and bone-implant contact) datasets were evaluated non-parametrically, as a normal distribution could not be assumed. Since each goat received all implants types (cubic, cubicHA, cubicBR, and TiPs), the experiment has a paired design with four groups. All datasets were evaluated with Friedman's repeated measures analysis of variance by ranks followed by Wilcoxon's signed-rank test. For all datasets, differences between medians were considered statistically significant for $P \leq 0.05$. Statistical analysis was performed using SPSS 16.0 software (SPSS Inc., Chicago, IL, US).

\section{Results}

\subsection{Surface characterization}

The surface morphology before implantation showed the characteristic appearances of non-coated and HA and brushite coated cubic specimens (Fig. 2). The coating thickness of both coatings analyzed by SEM was $15 \pm$ $5 \mu \mathrm{m}$. EDS analysis confirmed the presence of hydroxyapatite and brushite on the cubicHA and cubicBR surfaces, respectively (Fig. 3). The roughness measurements showed an average surface roughness ( $\mathrm{Ra}$ ) of $5.77 \mu \mathrm{m}$ for the cubic structure, $4.43 \mu \mathrm{m}$ for the cubicHA, $5.29 \mu \mathrm{m}$ for the 

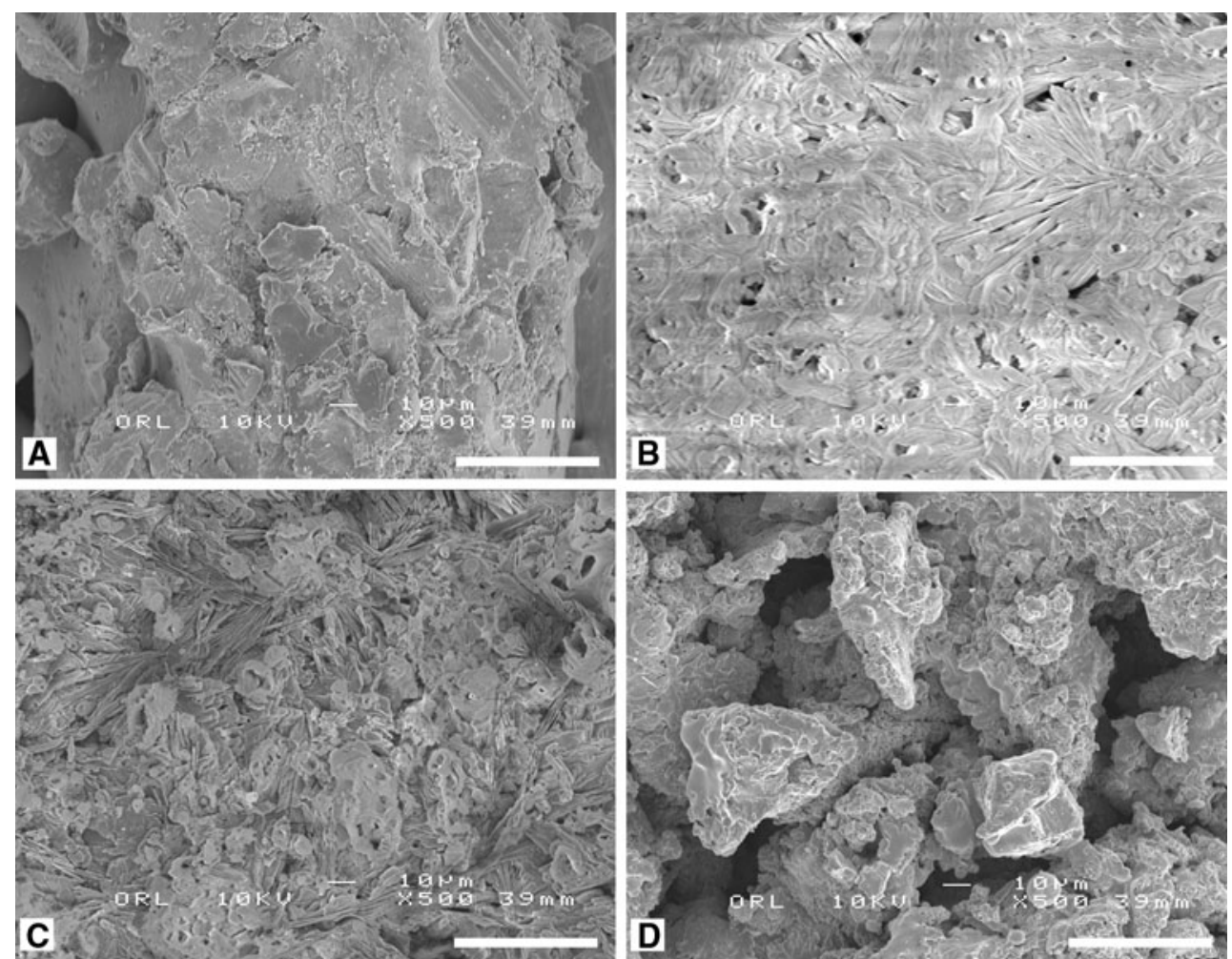

Fig. 2 Surface characterization. SEM images of the cubic (a), cubicHA (b), cubicBR (c) and TiPS (d) implant surfaces. Bar $=50 \mu \mathrm{m}$

Fig. 3 EDS analysis. EDS analysis confirming the presence of hydroxyapatite and brushite on the cubicHA (a) and cubicBR (b) surfaces
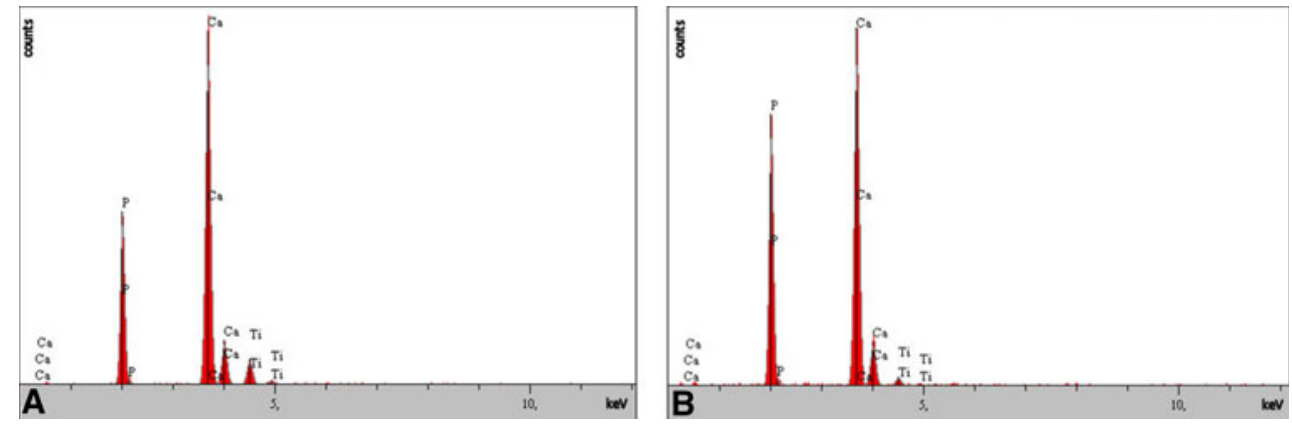

cubicBR and $6.64 \mu \mathrm{m}$ for the titanium plasma sprayed surface.

The in vitro coating dissolution analysis showed that the dissolution behavior presented periods of dissolution and recrystallization during the in vitro test with predominance of dissolution. The biomimetic coatings presented dissolution immediately after their immersion in $\mathrm{pH}$ 5.5. Both hydroxyapatite and brushite showed almost full dissolution of the deposited layer within the first days of immersion in $\mathrm{pH}$ 5.5. In $\mathrm{pH} 7.3$ the dissolution process did not start immediately (Fig. 4). The brushite coating was completely dissolved after exposure to $\mathrm{pH} 7.3$ at the end of the test, but HA coated specimens exposed to $\mathrm{pH} 7.3$ showed that the coating is not completely dissolved after 21 days (Fig. 5).

\subsection{Mechanical testing}

At 3 weeks after implantation no differences in mechanical strength of the bone implant interface were found. At 15 weeks the cubic $(P=0.043)$ and cubicHA structure $(P=0.043)$ had significantly higher mechanical strength at the interface compared to the Ti plasma spray coated specimens (Fig. 6a).

\subsection{Histology (Fig. 7)}

The bone ingrowth depth at 5 and 15 weeks after implantation was significantly larger for cubicHA $(P=0.028$ and $P=0.018$ respectively) and cubicBR $(P=0.028$ and 

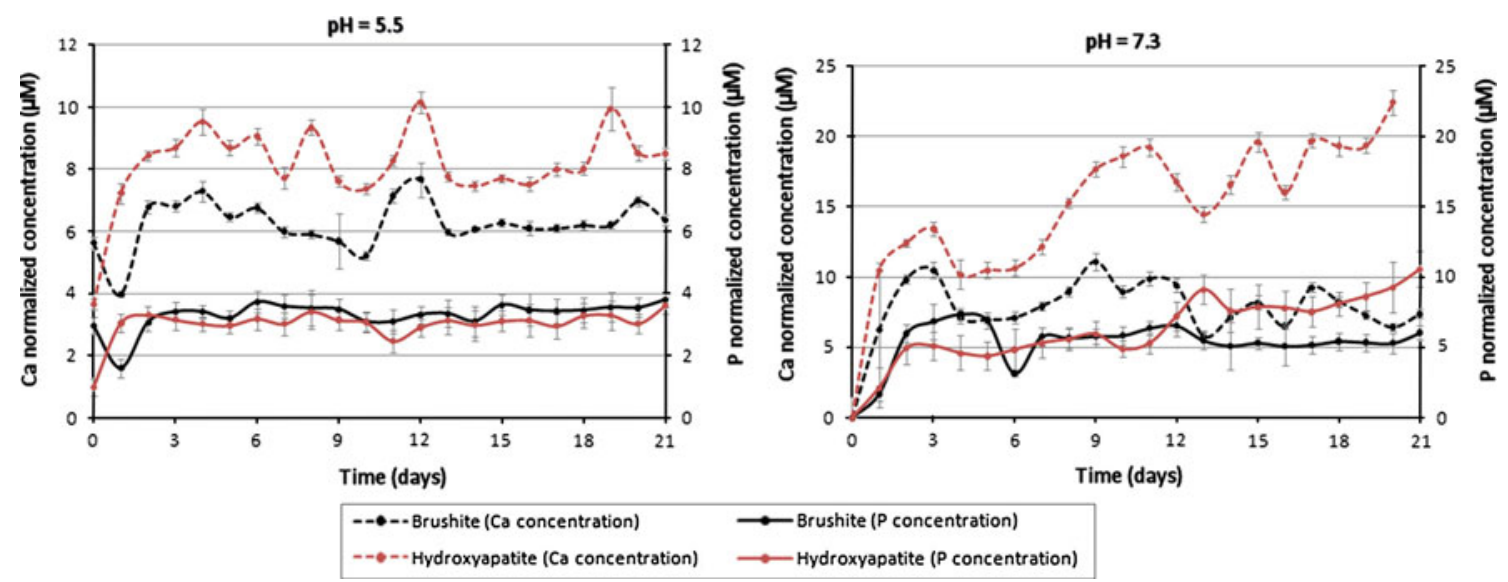

Fig. $4 \mathrm{Ca}$ and $\mathrm{P}$ concentration after immersion. $\mathrm{Ca}$ and $\mathrm{P}$ concentration after immersion of the specimens in pH 5.5 and 7.3 . Periods of dissolution and recrystallization occur during the in vitro test with predominance of dissolution
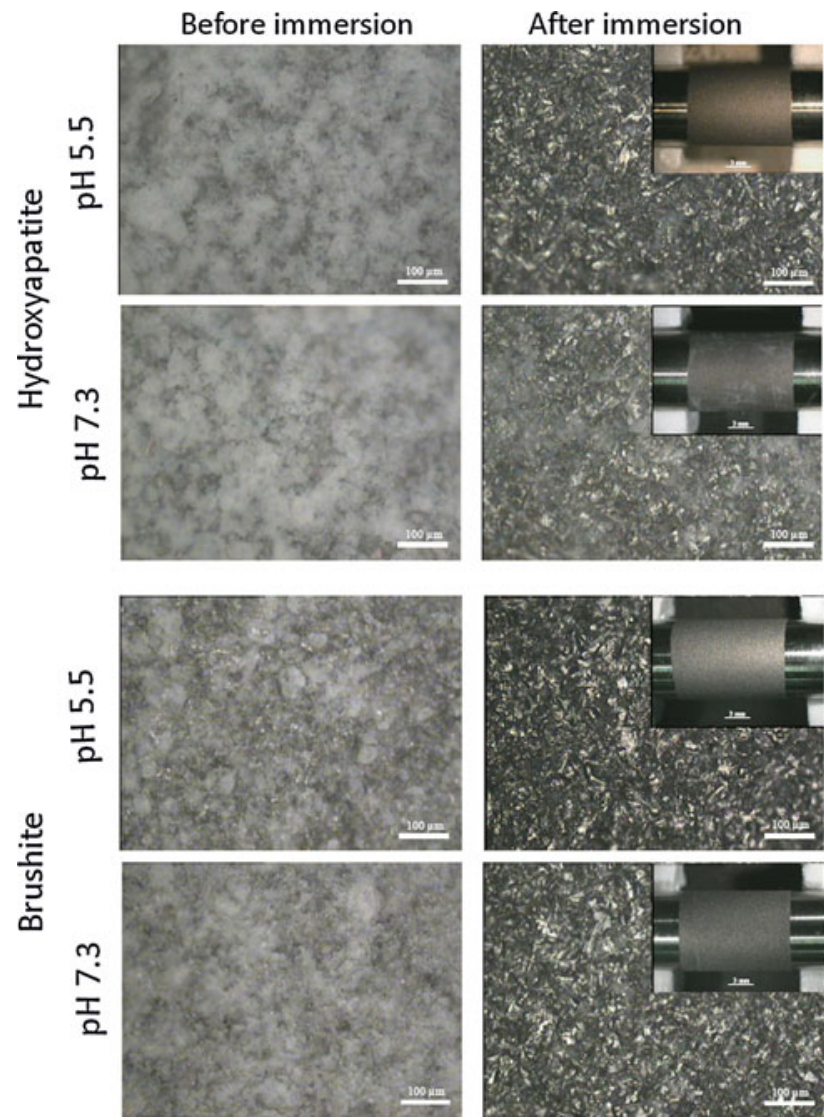

Fig. 5 Images of in vitro coating dissolution. Pictures of the specimens before and after immersion for the in vitro dissolution test. Both hydroxyapatite and brushite were completely dissolved after exposure to $\mathrm{pH}$ 5.5. After exposure to $\mathrm{pH} \mathrm{7.3,} \mathrm{the} \mathrm{brushite}$ coating was completely dissolved, but the HA coating was not completely dissolved at the end of the test. (The remaining $\mathrm{CaP}$ coating on the substrate has a light-opaque colour, Bar $=100 \mu \mathrm{m}$ )

$P=0.018$ respectively) compared to the cubic. At 15 weeks ingrowth depth of cubicBR was significantly higher than cubicHA $(P=0.043)$ (Fig. 6b).
With respect to direct bone implant contact no significant differences between the four groups of implants were found (Fig. 6c).

\subsection{Coating dissolution}

SEM analysis of the embedded hydroxyapatite and brushite coated specimens and their surrounding bone showed that the HA coating was still visible in some areas 3 weeks after implantation. In other areas no HA coating could be detected. At 15 weeks very little spots with HA coating were seen as most of the coating was dissolved. With respect to the brushite coated specimens, no coating could be found at 3 and 15 weeks.

\section{Discussion}

Two different $\mathrm{CaP}$ coatings were added to E-beam structures to enhance the bone ingrowth potential in an attempt to overcome the disadvantage of the prolonged time in which full bone ingrowth can be reached in highly porous structures. Although no differences between the coated and uncoated cubic structure were found for direct boneimplant contact and mechanical push out strength, addition of hydroxyapatite or brushite to the E-beam structure resulted in significantly greater bone ingrowth depth. Thus, addition of biomimetic $\mathrm{CaP}$ coatings appears to enhance bone ingrowth. With respect to the acceleration of bone ingrowth, significantly greater ingrowth depth at 5 weeks suggests the acceleration of bone ingrowth by addition of a calcium phosphate coating to the porous E-beam structure.

The absence of load in this model is a limitation of this study. Especially with regard to early bone ingrowth (and its acceleration) load bearing is an important factor [6, 31]. 

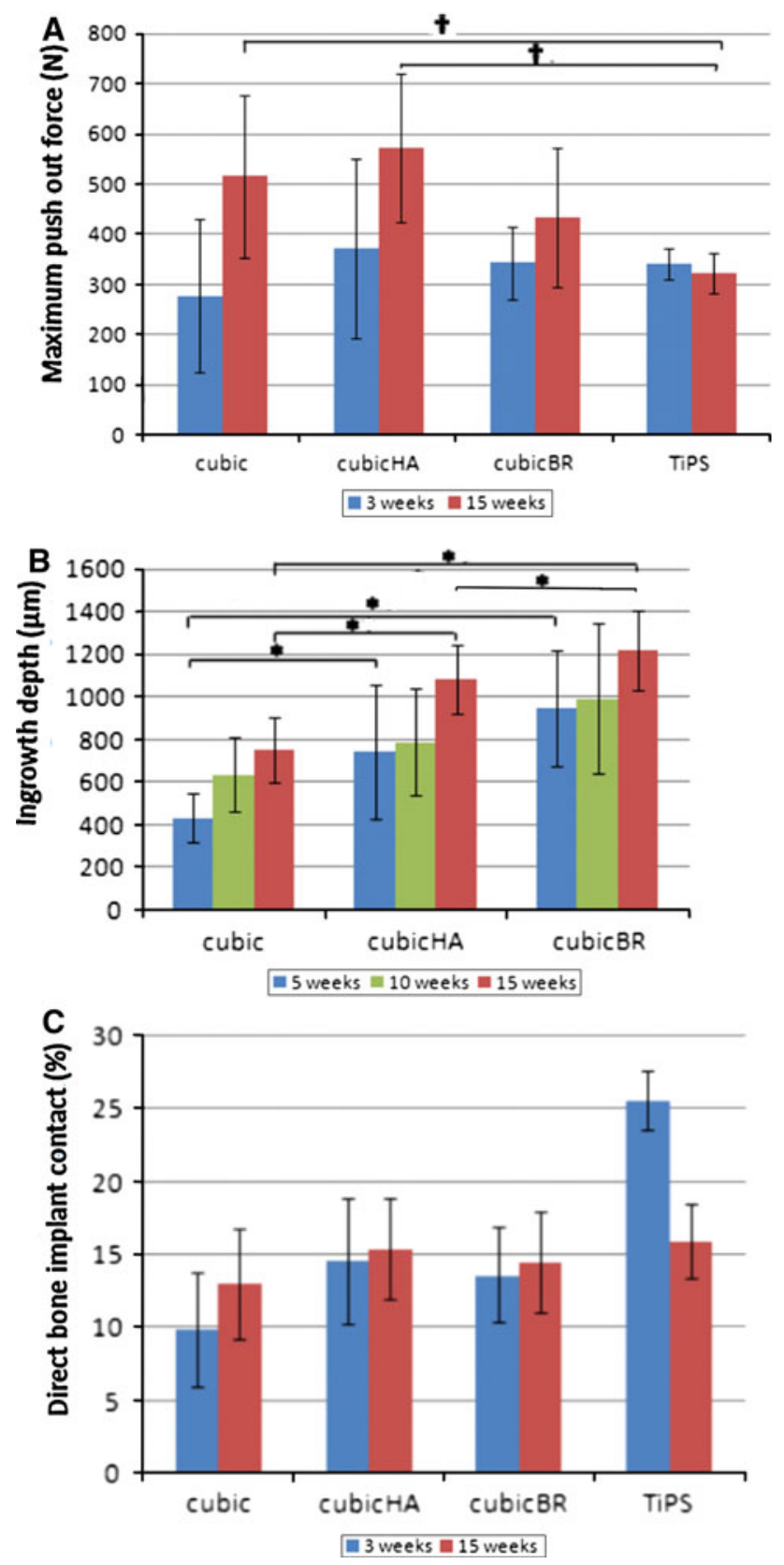

Fig. 6 Results. Results of mechanical (a) and histological analysis of bone ingrowth. Histological analysis consisted of bone ingrowth depth (b) and percentage direct bone implant contact (c). ${ }^{\dagger} P=$ $0.043 ; * P \leq 0.05$

Furthermore only one three-dimensional E-beam structure was tested.

Several groups tested porous structures in combination with $\mathrm{CaP}$ coatings and reported similar findings as the present study. Bone ingrowth of a porous tantalum structure with a biomimetic coating was significantly higher for coated specimens than for uncoated specimens at different time points [22]. Tsukeoka et al. [21] investigated the effect of the incorporation of hydroxyapatite into a titanium fiber mesh and found an increased push-out strength at 3 and 5 weeks, whereas after 8 weeks, no differences between specimens with and without hydroxyapatite were found. Porous titanium plugs implanted in a rabbit femur showed a significant increase in bone ingrowth for HA coated implants compared to uncoated implants after 6 weeks [19]. Furthermore, the study of Tsukeoka et al. [21] supports our findings with regard to the speed of bone ingrowth, that suggests that calcium phosphate coatings work as an accelerator of bone ingrowth.

Dissolution analysis in vitro and in vivo show that the brushite coating was completely dissolved after 3 weeks, whereas only a minority of the hydroxyapatite coating was present at that time. However, in vivo the effect of the addition of both $\mathrm{CaP}$ coatings was still visible after 15 weeks. This prolonged effect could be explained by initial osteoblast activation induced by coating degradation and release of calcium and phosphate ions, that also might act as a reservoir for new synthesis of HA [32, 33].

The attachment between the biomimetic coating and the implant might be weaker than the attachment between the bone and the coating. This can be seen in other calcium phosphate coatings as well. However, because of the intended use of this coating on porous, three-dimensional structures, where the long term fixation will be maintained by the interlock between bone and implant, this weaker attachment of the coating to the implant appears to be not a problem [34]. Part of the coating might chip off during press-fit implantation due to the weaker attachment between the coating and the implant. This loss of coating may not be so disadvantageous because the fragmented coating will remain in the surroundings of the implant [35].

Three different methods to assess bone ingrowth potential were used in the present study; a push-out test for mechanical evaluation of the bone-implant interface and two methods for histological analysis (bone ingrowth depth and percentage direct bone implant contact). Both histological methods have a different focus and it is difficult to say which one best defines bone ingrowth. Therefore, these two methods become more valuable when compared with the results of the push-out test that represents the actual mechanical strength at the bone-implant interface. In our study there was less agreement between the BIC measurements and the push out test. One could suggest therefore that BIC is not a good method to assess the effect of bone ingrowth on mechanical strength. This suggestion has been reported in literature as well [36]. Correlation between bone ingrowth depth and mechanical strength of the bone-implant interface is likely to be influenced by the fact that ingrowth beyond a certain depth does not enhance the strength of the bone-implant interface, similar as seen for the cement-bone interface [37]. 

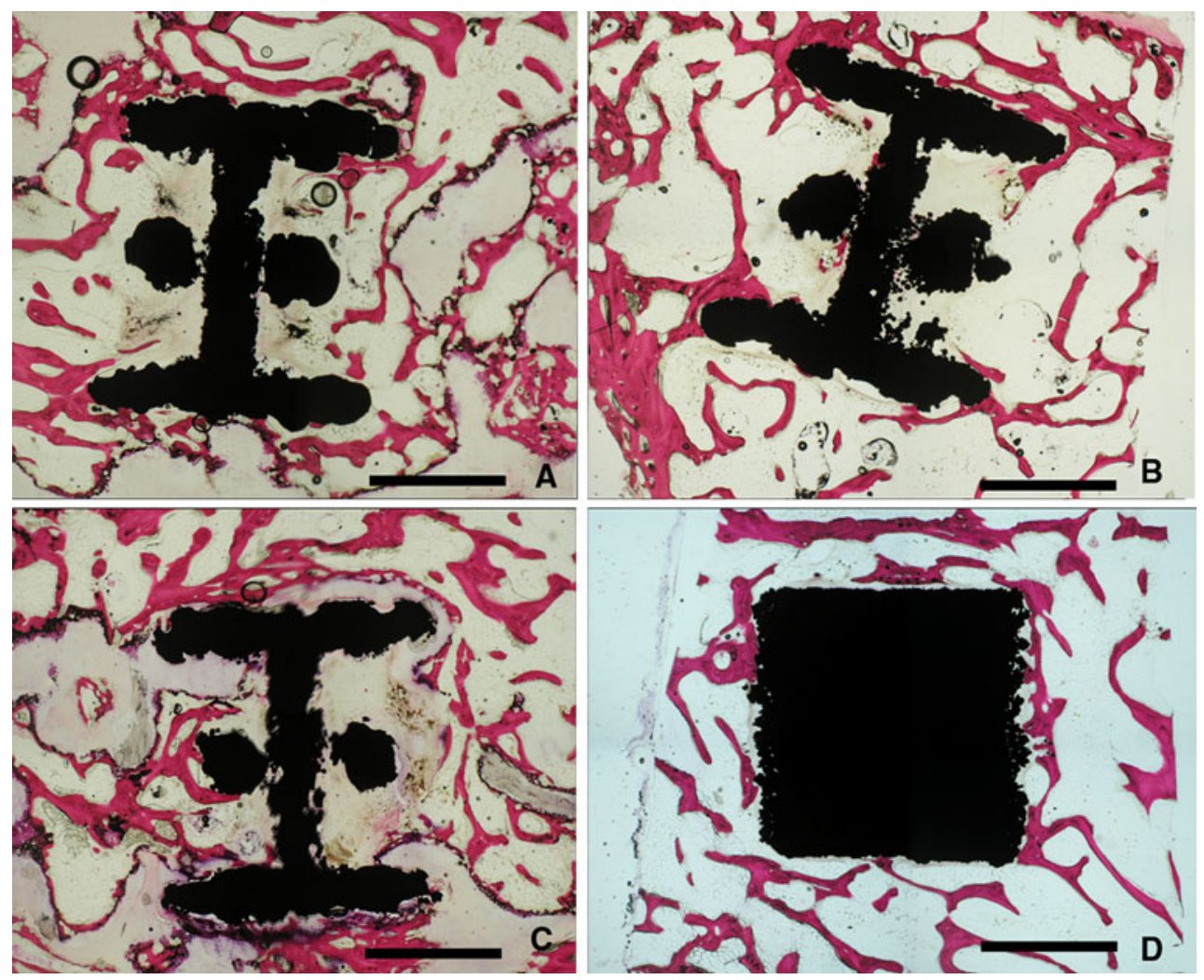

Fig. 7 Histology. Histological images of cubic (a), cubicHA (b), cubicBR (c) and TiPS (d). Bar = $2 \mathrm{~mm}$

In conclusion, the porous E-beam surface structure showed higher bone ingrowth potential compared to a conventional titanium plasma spray coating after 15 weeks of implantation. Based on histology findings, addition of a biomimetic calcium phosphate coating to the E-beam structure enhances bone ingrowth significantly. The biomimetic calcium phosphate coating appears to work as an accelerator of bone ingrowth.

Acknowledgments This study is cosponsored by Provincia Autonoma di Trento and Eurocoating SpA, Trento, Italy which designed the new surface structures. The authors thank Pierfrancesco Robotti, Emanuele Magalini and Giacomo Bianchi (Eurocoating, Trento, Italy) who actively participated in developing this study. The authors thank Willem van de Wijdeven and Léon Driessen for their technical assistance and the staff of the central animal facility of the Radboud University Nijmegen for their assistance in the animal experiments.

Open Access This article is distributed under the terms of the Creative Commons Attribution Noncommercial License which permits any noncommercial use, distribution, and reproduction in any medium, provided the original author(s) and source are credited.

\section{References}

1. Eskelinen A, Remes V, Helenius I, Pulkkinen P, Nevalainen J, Paavolainen P. Uncemented total hip arthroplasty for primary osteoarthritis in young patients: a mid-to long-term follow-up study from the Finnish Arthroplasty Register. Acta Orthop. 2006;77:57-70.

2. Karrholm J, Garellick G, Herberts P. Annual Report 2006. Swedish National Hip Arthroplasty Register. 2007.

3. McAuley JP, Szuszczewicz ES, Young A, Engh CA Sr. Total hip arthroplasty in patients 50 years and younger. Clin Orthop Relat Res. 2004;418:119-25.

4. Bragdon CR, Doherty AM, Rubash HE, Jasty M, Li XJ, Seeherman H, Harris WH. The efficacy of BMP-2 to induce bone ingrowth in a total hip replacement model. Clin Orthop Relat Res. 2003;417:50-61.

5. Geesink RG, de Groot K, Klein CP. Bonding of bone to apatitecoated implants. J Bone Joint Surg Br. 1988;70:17-22.

6. Kienapfel H, Sprey C, Wilke A, Griss P. Implant fixation by bone ingrowth. J Arthroplasty. 1999;14:355-68.

7. Bobyn JD, Pilliar RM, Cameron HU, Weatherly GC. The optimum pore size for the fixation of porous-surfaced metal implants by the ingrowth of bone. Clin Orthop Relat Res. 1980;150: 263-70.

8. Gauthier O, Bouler JM, Aguado E, Pilet P, Daculsi G. Macroporous biphasic calcium phosphate ceramics: influence of macropore diameter and macroporosity percentage on bone ingrowth. Biomaterials. 1998;19:133-9.

9. Karageorgiou V, Kaplan D. Porosity of 3D biomaterial scaffolds and osteogenesis. Biomaterials. 2005;26:5474-91.

10. Jones JR, Ehrenfried LM, Hench LL. Optimising bioactive glass scaffolds for bone tissue engineering. Biomaterials. 2006;27: 964-73.

11. Bobyn JD, Stackpool GJ, Hacking SA, Tanzer M, Krygier JJ. Characteristics of bone ingrowth and interface mechanics of a new porous tantalum biomaterial. J Bone Joint Surg Br. 1999;81: 907-14. 
12. Wennerberg A, Albrektsson T. Structural influence from calcium phosphate coatings and its possible effect on enhanced bone integration. Acta Odontol Scand. 2009;31:1-8.

13. Heinl P, Muller L, Korner C, Singer RF, Muller FA. Cellular Ti-6Al-4V structures with interconnected macro porosity for bone implants fabricated by selective electron beam melting. Acta Biomater. 2008;4:1536-44.

14. Parthasarathy J, Starly B, Raman S, Christensen A. Mechanical evaluation of porous titanium (Ti6Al4V) structures with electron beam melting (EBM). J Mech Behav Biomed Mater. 2010;3: 249-59.

15. Thomsen P, Malmstrom J, Emanuelsson L, Rene M, Snis A. Electron beam-melted, free-form-fabricated titanium alloy implants: material surface characterization and early bone response in rabbits. J Biomed Mater Res B Appl Biomater. 2009;90:35-44.

16. Ponader S, Vairaktaris E, Heinl P, Wilmowsky CV, Rottmair A, Korner C, Singer RF, Holst S, Schlegel KA, Neukam FW, Nkenke E. Effects of topographical surface modifications of electron beam melted Ti-6Al-4V titanium on human fetal osteoblasts. J Biomed Mater Res A. 2008;84:1111-9.

17. Biemond JE, Aquarius R, Verdonschot N, Buma P. Frictional and bone ingrowth properties of engineered surface topographies produced by electron beam technology. Arch Orthop Trauma Surg. 2010;20:47.

18. Habibovic P, Barrère $F$, van Blitterswijk CA, De Groot K, Layrolle P. Biomimetic hydroxyapatite coating on metal implants. J Am Ceram Soc. 2002;85:517-22.

19. Redepenning J, Schlessinger T, Burnham S, Lippiello L, Miyano J. Characterization of electrolytically prepared brushite and hydroxyapatite coatings on orthopedic alloys. J Biomed Mater Res. 1996;30:287-94.

20. Sun L, Berndt CC, Gross KA, Kucuk A. Material fundamentals and clinical performance of plasma-sprayed hydroxyapatite coatings: a review. J Biomed Mater Res. 2001;58:570-92.

21. Tsukeoka T, Suzuki M, Ohtsuki C, Tsuneizumi Y, Miyagi J, Sugino A, Inoue T, Michihiro R, Moriya H. Enhanced fixation of implants by bone ingrowth to titanium fiber mesh: effect of incorporation of hydroxyapatite powder. J Biomed Mater Res B Appl Biomater. 2005;75:168-76.

22. Barrere F, van der Valk CM, Meijer G, Dalmeijer RA, de Groot $\mathrm{K}$, Layrolle P. Osteointegration of biomimetic apatite coating applied onto dense and porous metal implants in femurs of goats. J Biomed Mater Res B Appl Biomater. 2003;67:655-65.

23. Davis JR. Coatings. In: Davis Associates, editor. Handbook of Materials for Medical Devices. Ohio: ASM international; 2005. p. 179-94.
24. Liu Y, Wu G, de Groot K. Biomimetic coatings for bone tissue engineering of critical-sized defects. J R Soc Interface. 2010; in press.

25. Heinl P, Rottmair A, Körner C, Singer R. Cellular titanium by selective electron beam melting. Adv Eng Mater. 2007;9:360-4.

26. De Palma F, Erriquez A, Rossi R, Spinelli M. Duofit total hip arthroplasty: a medium-to long-term clinical and radiographic evaluation. J Orthop Traumatol. 2007;8:117-22.

27. Kumar M, Dasarathy H, Riley C. Electrodeposition of brushite coatings and their transformation to hydroxyapatite in aqueous solutions. J Biomed Mater Res. 1999;45:302-10.

28. McDowell H, Gregory TM, Brown WE. Solubility of $\mathrm{Ca} 5(\mathrm{PO} 4) 3 \mathrm{OH}$ in system $\mathrm{Ca}(\mathrm{OH}) 2-\mathrm{H} 3 \mathrm{PO} 4-\mathrm{H} 2 \mathrm{O}$ at 5, 1025 and $37^{\circ}$ C. J Res Natl Bur Stand (Phys Chem). 1977;81A:273-81.

29. Schouten C, Meijer GJ, van den Beucken JJ, Leeuwenburgh SC, de Jonge LT, Wolke JG, Spauwen PH, Jansen JA. In vivo bone response and mechanical evaluation of electrosprayed $\mathrm{CaP}$ nanoparticle coatings using the iliac crest of goats as an implantation model. Acta Biomater. 2010;6:2227-38.

30. Dhert WJ, Verheyen CC, Braak LH, de Wijn JR, Klein CP, de Groot K, Rozing PM. A finite element analysis of the push-out test: influence of test conditions. J Biomed Mater Res. 1992;26: 119-30.

31. Chang YS, Oka M, Kobayashi M, Gu HO, Li ZL, Nakamura T, Ikada Y. Significance of interstitial bone ingrowth under loadbearing conditions: a comparison between solid and porous implant materials. Biomaterials. 1996;17:1141-8.

32. Becker P, Neumann HG, Nebe B, Luthen F, Rychly J. Cellular investigations on electrochemically deposited calcium phosphate composites. J Mater Sci Mater Med. 2004;15:437-40.

33. Reigstad O, Franke-Stenport V, Johansson CB, Wennerberg A, Rokkum M, Reigstad A. Improved bone ingrowth and fixation with a thin calcium phosphate coating intended for complete resorption. J Biomed Mater Res B Appl Biomater. 2007;83:9-15.

34. Kuroda S, Virdi AS, Li P, Healy KE, Sumner DR. A low-temperature biomimetic calcium phosphate surface enhances early implant fixation in a rat model. J Biomed Mater Res A. 2004;70: 66-73.

35. Hägi TT, Enggist L, Michel D, Ferguson SJ, Liu Y, Hunziker EB. Mechanical insertion properties of calcium-phosphate implant coatings. Clin Oral Implants Res. 2010; in press.

36. Moriyama Y, Ayukawa Y, Ogino Y, Atsuta I, Todo M, Takao Y, Koyano K. Local application of fluvastatin improves peri-implant bone quantity and mechanical properties: a rodent study. Acta Biomater. 2010;6:1610-8.

37. Majkowski RS, Bannister GC, Miles AW. The effect of bleeding on the cement-bone interface. An experimental study. Clin Orthop Relat Res. 1994;299:293-7. 